\title{
Más aportaciones para el estudio de la aljama hebrea de la villa de Ágreda
}

\author{
M. a Pía Senent Diez *
}

\begin{abstract}
RESUMEN
ABSTRACT

Se aportan nuevos datos sobre la

New data about the Jewish Synagogue aljama judía de Àgreda (Soria) en of Ágreda (Soria) are provided, based on documents found in the town's base a la documentación conservada en el Archivo Municipal de la villa y varios estudios inéditos realizados en consecuencia con los seguimientos arqueológicos relacionados con las restauraciones del edificio de la "Sinagoga" y de las murallas. Se aportan datos relativos a la Carta

Real de Merced de los Reyes

Católicos sobre la sinagoga, transcribiendo su dos versiones. Se analiza la familia de prestamistas judios de la villa documentada en las referencias del registro de escribanos y se identifican los restos de una Biblia hebrea que se conserva en el Ayuntamiento de Ágreda. PALABRAS CLAVE: Ágreda, Soria, sinagoga, prestamista, registro de escribanos, Biblia hebrea. archive, and in some unpublished reports about the archaeological works of restoration of the Synagogue and the town walls. Information is provided about the Royal Act of Grace of The Catholic Kings to the Synagogue, transcribing its two versions. The town Jewish moneylender's family is analysed in notary's documents of their Registry as well as the rests of a Hebrew Bible found in the town council.
\end{abstract}

* Directora del Archivo Histórico Provincial de Soria. 
La villa fronteriza de Ágreda, paso obligado entre los reinos de Aragón y Castilla, ha sido una constante en la historia de España pero "pocas ciudades españolas de su mismo orden pueden ofrecer un conjunto tan considerable y un núcleo tan compacto de documentación interesante como la que se guarda hoy en sus Archivos" ' 1 . Estos archivos siguen siendo una fuente de información muy valiosa desde la época medieval hasta nuestros días, aportando datos relativos a las minorias étnicas de la zona como fueron moros y judíos.

La presente comunicación trata de aportar nuevos datos sobre la aljama judía de Ágreda presentando varios documentos que nos la ilustran.

1. A partir de la repoblación cristiana de Ágreda por Alfonso VII, el Emperador, se desarrolla la estructura urbana de la villa cuyo recinto ha llegado hasta nosotros estructurado en cuatro zonas yuxtapuestas configurando una morfología muy especial.

El primer estudio promenorizado del recinto urbano de Ágreda lo realizó Juan Antonio Gaya Nuño ${ }^{2}$ diseñando un plano de la villa sobre la base de ciertos documentos tardíos del siglo XV que diferenciaba los diversos recintos en función de las etnias y de la religión de sus habitantes. Según esto los musulmanes ocuparian el recinto de la Muela en la margen derecha del río Queiles, los cristianos ocuparían la margen norte del río donde hoy se encuentran las iglesias de los Milagros y de Magaña en un recinto fortificado enfrentado a otro recinto musulmán ubicado en la Muela. En la zona sur de la villa se asentarían también los judíos ocupando una aljama en la zona más alta del recinto en el entorno de la calle Zapatería, iglesia de la Peña y calle del Hospital. A partir de la cubrición del río Queiles en el siglo XVi se dividió el entorno urbano construyéndose una serie de puertas que aislaron a las diversas etnias.

Otros autores identifican tres sectores sin advertir la independencia del recinto de la Peña y San Miguel y los adscriben a las diferentes etnias. La Muela sería el barrio árabe, San Juan el barrio cristiano y los judios ocuparían una zona difusa en el entorno de la Peña. Benito Martín señala la existencia en época altomedieval de los cuatro recintos que quedan determinados por los diversos tramos de la muralla y las rondas exterior e interior de la misma sobre las que se adosaron construcciones desde el siglo $\mathrm{xV}$.

'Sanchez Belda, L.: «Los Archivos de Ágreda". Rev. Celtiberia. Centro de Estudios Sorianos, n. ${ }^{\circ}$ 3. Año 11. Vol. II, enero-junio 1952.

2 GaYa NuÑo, J. A.: "La Muela de Ágreda. Restos de la aimedina fortificada y de la aljama hebrea». Bol. de la Academia de la Historia. Tomo CVI, cuaderno $1 .{ }^{\circ}$. Madrid, 1935. 
La separación étnica era poco frecuente en Castilla hasta épocas muy tardias (fines del siglo XIV o principios del XV) y Ágreda no debió de ser una excepción pese a lo mantenido por la historiografía tradicional. De lo que no cabe duda es que los judíos carecieron de una aljama separada del resto de la población cristiana mezclándose con ella en el recinto de la Peña y San Miguel pese al decreto dictado por Don Fernando de Antequera en 1406 y la orden del obispo para determinar un espacio que debía de ser ocupado por la aljama judia. El propio Ayuntamiento de Agreda notificó al monarca que los judíos de Ágreda nunca vivirían separados del resto de la población de la villa ${ }^{3}$.

La Real Merced del $1493^{4}$ dictada por los Reyes Católicos concedía al Concejo de Ágreda, en determinadas condiciones, el edificio de la sinagoga confiscada a los judíos tras los decretos de expulsión para ser usada como sede del Ayuntamiento. Sin embargo, en 1508 el Concejo de Ágreda seguía reunido en el atrio de la iglesia de San Juan, siendo convocados «a campana tañida" de la iglesia de San Pedro ${ }^{5}$.

Tradicionalmente se conoce como sinagoga un edificio de una sola nave, de mampostería y entrepaños de ladrillo, con un sobrio ábside semicircular, con rebanco alto y alero sin canecillos que está datado en la primera mitad del siglo XII. El problema radica en la falta de constatación de esta tradición popular. José Antonio Gaya Nuño, primer autor que estudia la morfología del edificio, le cuesta entender una sinagoga de tan reducido tamaño, con una orientación típica de las iglesias cristianas y con un marcado estilo románico. La documentación histórica de Ágreda señala la existencia de seis iglesias en la villa: Los Milagros, la Peña, San Miguel, San Juan, Magaña y San Pedro, perfectamente localizadas, si bien este edificio podría tratarse de otra iglesia de reducido tamaño cuya documentación no nos ha llegado. Tampoco tenemos ninguna referencia al culto que se celebrase en este edificio ni han aparecido enterramientos tanto en el interior como en el exterior del mismo tal como es la costumbre en las iglesias medievales cristianas.

\footnotetext{
a Benito Martin, F.; Gonzalez Diaz, A.; Pedroso Bravo, A.; Papin, C.: Murallas de Ágreda: estudio técnico. Junta de Castilla y León, Consejería de Cultura y Bienestar Social, Dirección General de Patrimonio y Promoción Cultural. Soria, 1992. (Inédito).

4 Existen dos ejemplares del documento, el original conservado en el Ayuntamiento de Ágreda y la copia del Registro General del Sello de Simancas. -Ver apéndice documental. Existen otros ejemplares de cesión de las sinagogas a los concejos como casa de ayuntamiento. En la zona geográfica estudiada el más conocido es Belorado (Burgos).

5 Archivo Histórico Provincial de Soria; Protocolos, n. ${ }^{\circ} 1.488$.
} 
Sin embargo, el propio Gaya Nuño, en 1935, ponía de relieve varios datos que avalaban la posibilidad de que estuviéramos ante el edificio de la sinagoga medieval de Ágreda: La ausencia de ventana ritual en la cabecera de un templo cristiano y la entrada que existió en la fachada oeste, frente al ábside, situación del acceso en varias sinagogas en oposición a las entradas laterales de las iglesias a través del muro sur. La absoluta pobreza de una aljama marginal en una zona rural como era Castilla que contrasta con la riqueza de los edificios empleados por los judios como sinagoga en otras regiones del centro y sur peninsulares. Esto justificaría la ausencia de recursos artísticos y el pequeño tamaño del edificio.

En 1955 el profesor Cantera señaló la existencia de una ventana en la cabecera del ábside que salió en la luz en el proceso de restauración del año 2000 cuando se limpió el enfoscado de esta zona ${ }^{6}$. Con respecto al acceso al edificio por el muro oeste, a los pies del mismo, los trabajos de rehabilitación imposibilitan establecer conclusiones definitivas ya que tanto el muro sur como el oeste están muy retocados en épocas posteriores.

El pasado año 2000 se llevó a cabo en el edificio de la sinagoga, una intervención arqueológica paralela a las obras de restauración. El estudio puso de relieve la existencia de restos de época romana, desde fines de la República o principios del Imperio, siendo abandonado el solar en el siglo $1 .^{\circ}$ de la era cristiana sin que se detecte otra ocupación hasta el siglo XII cuando se construye el edificio que hoy conocemos. Durante la intervención arqueológica no se hallaron restos que pudieran establecer conclusiones definitivas para adscribir el uso del edificio como sinagoga.

A partir de las descripciones contenidas en documentos podemos establecer la tipología de las sinagogas medievales del entorno geográfico de Castilla y León, La Rioja, Navarra, País Vasco y Aragón y las provincias de Guadalajara y Cuenca. En esta zona las sinagogas suelen ser salas rectangulares sin presbiterio marcado y con bóvedas de crucería (Miranda de Ebro, Burgos) o con bellos artesonados (Carrión de los Condes, Palencia) y sostenidas por columnas (Cifuentes, Guadalajara). Los motivos decorativos son inscripciones de textos sagrados (Cuenca) y cuentan con una galería elevada para mujeres (Hijar, Teruel). El aspecto exterior es modesto (Amusco, Palencia) y pueden ir precedidas de patio con jardín (Carrión de los Condes, Palencia).

A lo largo de los siglos el edificio fue remodelado para adecuarse a otros usos y se practicaron obras menores para adaptarlo. En él siglo xx,

6 Cantera, F.: «La sinagoga de Ágreda» en Sinagogas españolas. C.S.I.C. Madrid, 1955. 
desde la Guerra Civil, se documenta el empleo como Centro de Auxilio Social. Desde la década de los cincuenta, pasó a Centro Secundario de Higiene. En estos años se revocaron las paredes de cemento y se cerraron los dos ajimeces de los laterales del ábside. Posteriormente fue de nuevo abandonado llegando a un estado lamentable hasta que en el año 2000 se iniciaron labores de restauración para adaptarlo a usos hosteleros por una empresa privada?

2. El registro de escribanos del Archivo Municipal de Ágreda es, a juzgar por Sánchez Belda, una de las piezas más interesantes de la documentación que en él se conserva. No ha llegado completo pero existen alrededor de 500 folios agrupados en cuadernillos que debían constituir varios volúmenes. Su contenido son diferentes escrituras recibidas y otorgadas por los escribanos del Concejo entre 1338 y 1365 , lo que le convierte en uno de los registros de escribanía más antiguos de España. El soporte es papel muy grueso, típico del siglo XIV, sin filigrana y con letra gótica cursiva. Es un documento fundamental para el estudio de la historia de Ágreda por la gran cantidad de información, perdida en otras fuentes, que transcribe y el infinito número de asuntos que trata ${ }^{8}$.

Entre las escrituras contenidas en estos registros, se conservan varias relativas a la actividad de los judíos locales, entre ellos destaca una familia de prestamistas que compaginó las labores de vendedores de paños, telas y tejidos de lujo con los préstamos de dinero a los habitantes de Ágreda y de los pueblos del entorno. La mayoría de los préstamos documentados en Ágreda a mediados del siglo XIV, donde los judíos aparecen como prestamistas y moros y cristianos de todas las condiciones como endeudados, se deben a la necesidad de abonar los impuestos que los pecheros de la zona aportaban al fisco.

Los contratos de endeudamiento se firmaban ante el escribano público del Concejo y en presencia de testigos por ambas partes: Moros y cristianos por parte de deudor y judíos por parte del prestamista. Curiosamente, el testigo del prestamista era miembro de su familia, hijo, hermano, yerno o cuñado, y que en otras escrituras del registro aparece también prestando dinero en otros actos jurídicos somilares.

ARQUETIPO, S.C.L.: Restauración de «la sinagoga» de Ágreda: Informe de la intervención arqueológica. Junta de Castilla y León, Consejería de Educación y Cultura, Dirección General de Partrimonio y Promoción Cultural. Soria, 2000 (Inédito).

- Sánchez Belda, L.: "Los archivos de Ágreda". Rev. Celtiberia, Centro de estudios sorianos, ก. ${ }^{\circ}$, año II-Vol. II, enero-junio 1952. 
Siempre aparece un tercer personaje, el avalista del deudor, que suele obligar, antes de firmar como fiador, que se garanticen sus derechos y se le exculpe de responsabilidad garantizando que se le abonará lo adelantado en caso de ejecución del aval del préstamo.

El estudio de esta familia judía de Ágreda, dedicada a la banca, resulta fácil a través de las referencias que nos han llegado en estas escrituras notariales. Manuel Hurtado Quero publicó una reseña de la misma hace unos años, sin embargo un estudio más detallado permite ampliar las relaciones existentes entre ellos ${ }^{9}$.

Samuel de Arnedo, judío que por su apellido le hacemos originario de la Sierra de Cameros en La Rioja, tuvo tres hijos que vivieron a mediados del siglo XIV en Ágreda (Soria): Mosé, Çah y Nohem Ben Xeteni, que en los protocolos del Concejo de Ágreda aparece como Nombre Bueno Xeteni, romanceando el nombre hebreo. Los tres eran prestamistas, vendedores de paños y propietarios de bienes raíces en la comarca de Ágreda hacia 1340 documentándose sus negocios en varios asientos del registro de escribanos ${ }^{10}$. De los hijos de Samuel de Arnedo, el más activo fue Nombre Bueno Xeteni, casado con una señora llamada doña Oro que también se dedicó al negocio del préstamo de dinero a juzgar por la referencia del contrato que firmó ante el escribano en 1340.

Nombre Bueno Xeteni y doña Oro tuvieron varios hijos e hijas: Don Çeli, dedicado al comercio de paños, don Çah, prstamista que trabajaba con su hermano Osua actuando como testigo en los negocios de éste, y Osua, que en algunos documentos se le denomina Rabí Osua, y es sobre él que recae el peso del negocio familiar firmando diecisiete escrituras como prestamista, testigo de sus hermanos o de su cuñado y vendedor de paños, sin olvidar ciertos asuntos que tuvo con la justicia ya que sufrió una pesquisa por falsear los padrones del pecho de la fonsadera, siendo acusado y escribiendo las correspondientes alegaciones que fueron recogidas por el escribano del Consejo en Ágreda.

Osua tuvo hermanas casadas con dos judíos que intervinieron en los negocios familiares. Don Salomón, que se dice yerno de Nombre Bueno Xeteni y cuñado de Rabi Osua, y don Abraham, yerno de Xeteni. Ambos fueron prestamistas y, como toda su familia, vendedores de telas. Actúan

\footnotetext{
9 Hurtado Quero, M.: "Judios de Ágreda: Estudio de una familia de prestamistas a mediados del siglo xiv». Rev. Celtiberia, Centro de estudios sorianos, n. ${ }^{\circ} 73$, enero-junio 1987.

10 Archivo Municipal de Ágreda: Registro de escribanos. Protocolo de 1338-1339 y protocolo de 1339-1340.
} 
como banqueros cuando sus cuñados son sus testigos y como testigos cuando el negocio le corresponde a alguno de sus cuñados. El último de la saga es Niago, hijo de Rabí Osua, que aparece testificando en los negocios de sus parientes.

La familia Xeteni no fueron los únicos agredenses que se dedicaron al préstamo, otros judíos siguieron su ejemplo documentándose en el registro de escribanos otros nombre hebreos: Don Salomón de Burgos, don Salomón, el trapero, Salomón de Guadiex y el judío de Tarazona. En una ocasión encontramos a un judio endeudado llamado Mosé, hijo de Aleser que debe dinero en lugar de prestarlo ${ }^{11}$.

3. El fragmento de la Biblia hebrea conservado en el Archivo del Ayuntamiento de Ágreda (Soria), corresponde a un resto del Pentateuco de la Sinagoga de la villa, edificio que aparece documentado en dos textos de finales del siglo XV, cuando, a raíz de la expulsión, fue donado por los Reyes católicos al Concejo para ser empleado como Casa del Ayuntamiento.

El texto bíblico fue citado por don Francisco Cantera Burgos en dos artículos publicados en 1955 y 1976 respectivamente donde estudiaba la posible conservación del edificio de la Sinagoga y el trazado de la aljama hebrea de Ágreda ${ }^{12}$. Luis Sánchez Belda también lo citaba en un artículo de 1952 al referirse a los fondos de la Sección Histórica del Archivo Municipal ${ }^{13}$. Sin embargo, en ninguno de los dos estudios del Profesor Cantera se determina el pasaje al que pertenecía en concreto salvo una breve cita al Levítico. Sabemos que corresponde al final del libro del Livítico, desde el capítulo 26 , versículo 43 , más o menos ${ }^{14}$, hasta el final

1 El registro ha sido transcrito por RuBio SEMPER, A.: Fuentes medievales sorianas: Ágreda. Edición de la Exma. Diputación Provincial de Soria. Colección de archivos sorianos, $n{ }^{\circ} 1$. Soria, 1999.

12 «A la mencionada sinagoga de Ágreda Pudo pertenecer el trozo de cuero escrito con caracteres hebraicos a tres columnas que todavía se conserva en la que fue plaza fuerte entre Castilla y Aragón". CANERA BURGOS, F.: "La sinagoga de Ágreda», en Sinagogas españolas. C.S.I.C. Madrid, 1955.

«El Ayuntamiento posee también en su archivo un fragmento de Biblia hebrea, resto, al parecer, de un rollo de la Ley de aquella comunidad judia quizá de los siglos XIII o xiv: son tres columnas, una de ellas integra (50 lineas) y dos más, laterales, traccionadas, en letra española muy bella, sin vocales. El texto corresponde al Levítico." CANTERA BuRgos, F.: "Juderías medievales de la provincia de Soria" en Homenaje a Fray Justo Pérez de Urbel, OSB. Studia Silensia III. Santo Domingo de Silos, 1976.

13 Sánchez Belda, L.: «Los archivos de Ágreda». Rev. Celtiberia, Centro de Estudios Sorianos, n. 3 , año II, vol. II, enero-junio 1952

14 Resulta dificil determinar en concreto en principio y fin de Jas columnas, especialmente en los fragmentos laterales por el estado de conservación de los bordes superior e inferior de la pieza. 
del libro, capítulo 27, versículo 34, y principio del libro de los Números, capítulo 1, versículo 1 a 27 . El documento aparece mutilado de forma que sólo está completa la columna central que corresponde a Levítico 27, 1034 . El resto se intuye a través de los restos del texto, donde se aprecian principios y finales de las palabras que lo componían.

El Profesor Cantera señaló que se trataba de letra española, sin vocales, y podemos añadir que es un texto librario muy cuidado en mayúsculas no cursivas. La piel que sustenta el escrito pone de relieve el formato del libro. Un rollo de la Ley que se debía enrollar sobre si mismo a medida que se leía en la sinagoga. El fragmento presenta, todavía, las señales de haber sido conservado como rollo y no en forma de códice. La existencia de restos de este formato viene a confirmar la costumbre semita del rollo durante los siglos medievales y modernos frente a la costumbre cristiana de emplear códices de páginas encuadernadas.

Desconocemos la procedencia aunque el propio Cantera ya señalaba en 1955 que podría tratarse de la Torah de la sinagoga de Ágreda y que pasara al Ayuntamiento entre los bienes dejados por los judíos tras la expulsión en 1492, ya que según la documentación del propio Archivo municipal, el edificio de la sinagoga fue otorgado por los Reyes Católicos como Casa de Ayuntamiento al Concejo de la villa, conservándose desde entonces allí. La tradición popular ayuda muy poco en este asunto ya que la única referencia oral que hemos podido recoger consideraba que el texto se refería al libro de los Salmos, concretamente al número catorce, posibilidad totalmente descartada con una lectura somera del contenido. Por tanto, sabemos que a mediados del siglo $\mathrm{xx}$, el documento era ya conocido y divulgado por el Profesor Cantera Burgos y en la actualidad se conserva en el Archivo Municipal del Ayuntamiento de Ágreda después de haber sido restaurado en el Centro de Restauración de la Junta de Castilla y León en Simancas (Valladolid).

Sin embargo, por la mutilación que el cuero presenta a ambos lados, realizado por un objeto cortante, y en función de la costumbre que en la Edad Moderna, tras la expulsión de los judíos, se tenía de emplear libros con escritura hebrea para encuadernar códices y textos cristianos ya sean latinos como escritos en lenguas vernáculas. El corte del rollo de la Biblia de la sinagoga de Ágreda se debió a su uso como cubierta de otro libro y presenta, a juzgar por la forma y los agujeros, una tipología de cubierta tipo cartera, que cerraba el libro mediante una solapa atado con tiras de cuero. El fragmento se conservó como cubierta de un libro de actas del Ayuntamiento. El material de cuero sobre el que aparece el texto hace pensar en esta idea. La costumbre se documenta en el entorno geográfico 
a juzgar por los restos hallados en el Archivo de la Catedral de Calahorra. Se trata de cuatro fragmentos escritos en hebreo, correspondientes al libro del Éxodo, con signaturas n.os $1,2,3$ y 4 del catálogo de Fernando Bujanda donde se cita que "constituían cubiertas para los legajos formados por el archivista Gregorio Leal, por el cual fueron cortados a medida de los referidos legajos del mismo volumen". Situación similar la encontramos en el Archivo de la Archdiócesis de Burgos, donde Luciano Hiudobro localizó, como parte de las encuadernaciones de los libros de actas de la Cofradía de la Real de Burgos, varios fragmentos de documentos jurídicos de los judíos de Burgos, escritos en hebreo y muy deteriorados ${ }^{15}$.

\section{APÉNDICE DOCUMENTAL}

\section{1.493, enero, 27. Barcelona}

Carta Real de Merced ${ }^{16}$ de los Reyes Católicos concediendo al Concejo de Ágreda (Soria) la sinagoga dejada por los judíos de la Villa tras el Decreto de Expulsión para que ubique en dicho edificio las dependencias del Ayuntamiento.

Original en papel

Sello de Placa en el reverso

$220 \times 320 \mathrm{~mm}$.
Carta Real $n \cdot{ }^{\circ} 21$

Sección Histórica

Archivo Municipal de Ágreda

Don Fernando e Donna Ysabel, por la graçia de Dios, Rey e Reyna de Castilla, de León, de Aragón, de Seçilia, de Granada, de Toledo, de Valençia, de Galiçia, de Mallorca, de Sevilla, de Cerdenna, de Córdova, de Córçega, de Murçia, de Jahen, de los Algarbes, de Algezyra, de Gibraltar, de las Yslas de Canaria, Conde e Condesa de Barçelona e Sennores de Vizcaya e de Molina, Duques de Athenas e de Neopatria, Condes del Roysellón e de Cerdannia, Marqueses de Oristán e de Goçiano, por quanto por parte de vos el Conçejo, Justiçias, Regidores, Cavalleros, Escuderos, Ofiçiales e Omes Buenos de la Villa de Ágreda nos fue fecha relaçión diziendo que al tiempo que por nuestro mandado salieron los judíos de nuestros reynos mandamos a los dichos judios que non

15 Laredo, A. I.; Ben Malka, H. y Cantera, F.: «Miscelánea de documentos fragmentarios hebraicos". Rev. Sefarad, n. ${ }^{\circ} 4,1944$, Madrid. C.S.I.C

16 La Carta de Merced es un documento expedido por la Cancillería de los Reyes Católicos, tal como determinaron en las Cortes de Toledo de 1480, donde se conceden mercedes y aparecen firmando los propios reyes siendo, tan sólo refrendados por el secretario. Se caracterizan por llevar intitulación completa, señalando todos los reinos y dominios, dirección, encabezada por « $A$ vos...", notificación y exposición del motivo de la petición formulada por el interesado a los reyes, dispositivo, encabezado por "E tovímoslo por bien...", la fecha se encabeza por "Dada..." y es completa, señalando lugar, día, mes y año.

Las cartas reales llevan al dorso el refrendo del secretario, los derechos de expedición, número de registro y sello, firma del registrador y sello de placa con la firma de la persona que actuó como canciller. 
vendiesen las sinagogas nin onsarios e quedasen para hacer dellos lo que la nuestra merçed fuese según que esto e otras cosas más largamente en la dicha carta, aviedes comprado la dicha sinoga para faser Casa de Conçejo, e que por virtud de lo dicho vos fue embargada por ende que nos suplicáradeis e pediéradeis por nos que vos hiziéremos merçed de la dicha sinoga que asi los dichos judios dexaron para feser Casa de Conçejo e Ayuntamiento en la dicha Villa. E como la nuestra merçed fuere e nos tovímoslo por bien e por la presente sy en la aljama de los judíos desta dicha villa non avía madaveríes sytuados nin la cabeza del pecho nin en el serviçio e medio serviçio nin en las carneçerías della para yglesias o monasterios o para otras personas qualesquier que vos fasemos merçed de la dicha sinoga para que podáis faser e fagais en ella Casa de Ayuntamiento para esa dicha Villa e non para otra cosa alguna e quedáis obligados de la labrarse e tenerse reparada de la qual vos mandamos dar esta carta confirmada de nuestros nombres e sellada con nuestro sello. Dada en la Çibdad de Barçelona, a veynte a siete dias de enero de mil e quatroçientos e noventa a tres annos.

$$
\text { Yo, el Rey Yo, la Reyna }
$$

Yo, Juan de la Parra, ${ }^{17}$ Secretario del Rey e de la Reyna, nuestros Sennores, la fize escrivir por su mandado.

Merçed de la sinoga de Ágreda a la dicha Villa para Casa de Conçejo ${ }^{18}$

\title{
1.Bis 1493, enero, 27. Barcelona
}

Carta Real de Merced de los Reyes Católicos concediendo al Concejo de Ágreda (Soria) la sinagoga dejada por los judios de la Villa tras el Decreto de Expulsión para que ubique en dicho edificio las dependencias del Ayuntamiento ${ }^{19}$.

\author{
Registro General del Sello n. ${ }^{\circ}$ 1498-15 \\ Archivo General de Simancas \\ $240 \times 2340 \mathrm{~mm}$.
}

Ágreda

Merçed de la sinoga de los judíos

27 de enero de noventa e tres Consejo

Don Fernando e Donna Ysabel etc. Por quanto de parte de vos el Conçejo, Justiçias, Regidores, Cavalleros, Escuderos, Ofiçiales e Omes Buenos de la Villa de Ágreda nos

17 El secretario Juan de la Parra fue nombrado secretario de los Reyes Católicos por Carta Real de Merced dada en Écija el 9 de febrero de 1490. Dicho nombramiento se debió a Fernand Álvarez de que era el oficial principal, oficio que tuvo que compaginar con el de secretario pues en 1503 le solicitaron que librara, por cédula como "Secretario y oficial principal de Fernand Álvarez", 50.000 madaveríes anuales que percibía de ración y quitación. Su actividad fue iimportante en la Cancillería Real de los Reyes Católicos ya que son muchos los documentos que aparecen refrendados por este secretario.

${ }_{18}$ Transcripción: M. ${ }^{a}$ Pia Senent Díez, Directora del Archivo Histórico Provincial de Soria.

1927 enero 1493. Barcelona. Fol. 15

Merced, en ciertas condiciones, a la villa de Ágreda, de la sinagoga que compró a los judíos de ella, la cual según el decreto de expulsión, había de ser confiscada para la Cámara Real.- Reyes. Nota del Catálogo del Registro General del Sello del Archivo General de Simancas. 
fue fecha relaçión diziendo que al tiempo que por nuestro mandato salieron los judíos de nuestros reynos, mandamos a los dichos judíos que non vendiesen las synogas sin osarios y que quedasen para fazer dellos lo que nuestra merced fuere según que esto y otras cosas más largamente en la dicha manera que sobrello mandamos dar se contiene, e que antes que fuese la dicha carta avíades comprado la dicha synoga para facer Casa de Conçejo e que por virtud de la dicha nuestra carta vos fue embargada. Por ende que vos suplicárades e pidiérades por merçed que vos fizieramos merçed de la dicha synoga que asy los dichos judíos dexaron para fazer Casa de Conçejo e Ayuntamiento en esa dicha Villa e como la nuestra merçed fuese e nos tovímoslo por bien e por la presente sy en la aljama de los judíos desa dicha Villa non avía madavaríes situados en la cabeça del pecho nin en el serviçio e medio serviçio nin en las carneçerías della para yglesias o monasterios o para otras personas qualesquier vos fazemos merçed de la dicha synoga para que podays fazer e fagays della Casa de Ayuntamiento para esa dicha Villa e non para otra cosa alguna y quedáis obligados de la labrare e tenere reparada de lo qual vos mandamos dar esta carta firmada de nuestros nombres y sellada con nuestro sello. Dada en la Çibdad de Barçelona, a veynte e siete días de enero de mil e quatroçientos e noventa e tres annos.

$$
\text { Yo. El rey Yo, la Reyna }
$$

Yo, Juan de la Parra, Don Álvaro, Don Juan de Castañeda, el Doctor de Alcocer Chanciller, el Doctor de Oropesa. ${ }^{20}$

\section{$2^{\circ} \quad 1338-1340$}

\section{Registro de escribanos del Concejo de Ágreda Protocolos $^{21}$}

Original en Papel Sección Histórica

Cuadernillo $240 \times 340 \mathrm{~mm}$. Archivo Municipal de Ágreda

\section{3. ${ }^{\circ} \quad$ Siglos $X I I \circ X I V$}

Fragmento de rollo de cuero con escritura hebrea correspondiente a la Biblia de la Sinagoga de Ágreda (Soria). Texto de los capítulos 26 y 27 del libro del Levítico y $1 .^{\circ}$ del libro de los Números.

Original sobre cuero

Letra hebrea española

Tres columnas. Central completa

50 líneas por columna
Reg. $15 / 98$

Exp. 50-168

Archivo Municipal de Ágreda

Sección Histórica

\footnotetext{
20 Transcripción: M. a Carmen Vázquez Mateo, Ayudante del Archivo Histórico Provincial de Soria.

21 Transcrito y publicado por RuBIO SEMPER, A: Fuentes medievales sorianas: Ágreda. Edición de la Excma. Diputación Provincial de Soria. Colección de Archivos Sorianos, n. ${ }^{\circ}$. Soria, 1999.
} 


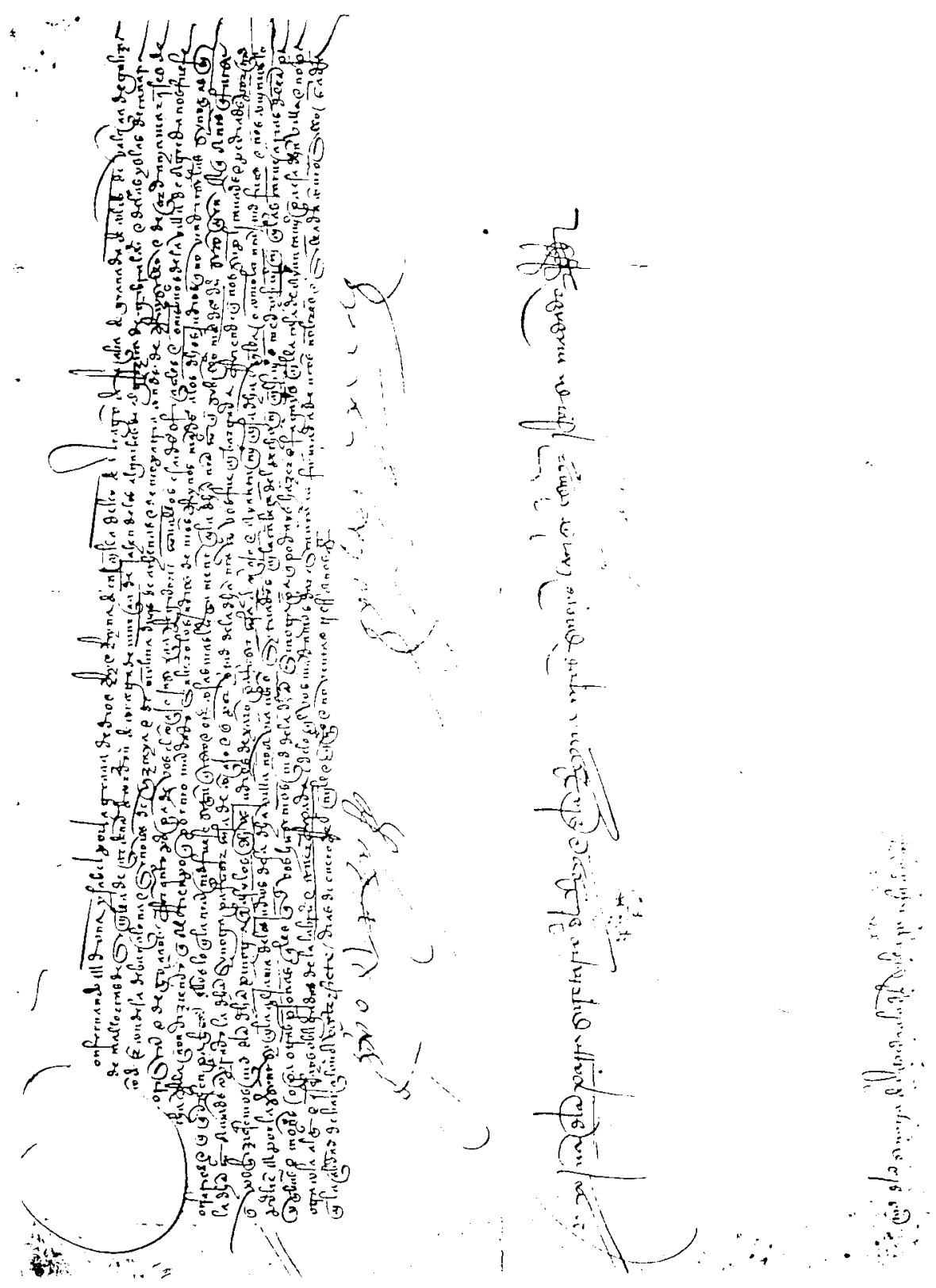

Apéndice 1. 

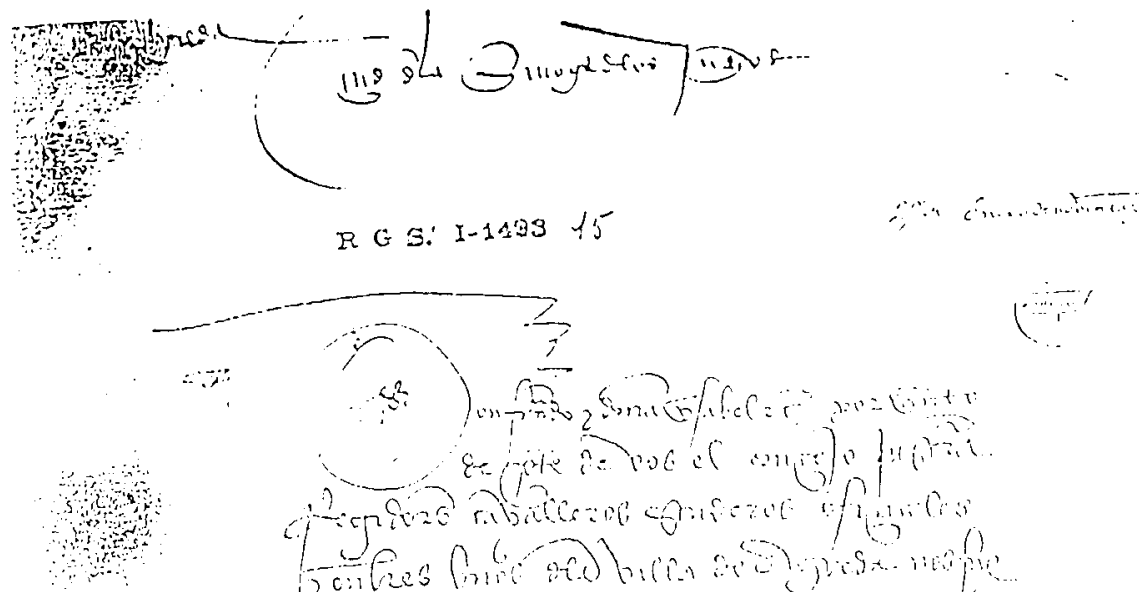

द.

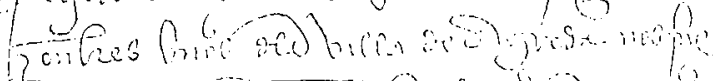

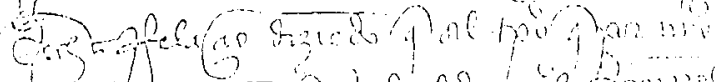

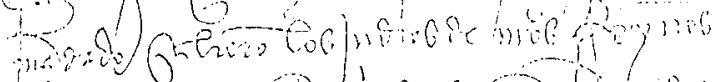

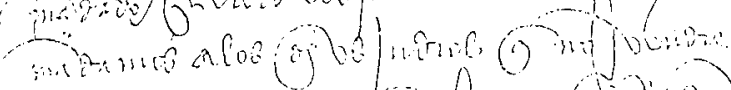

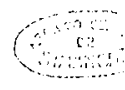

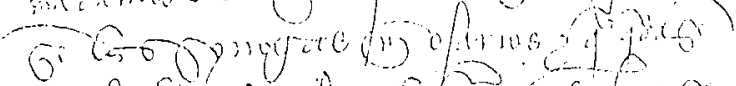

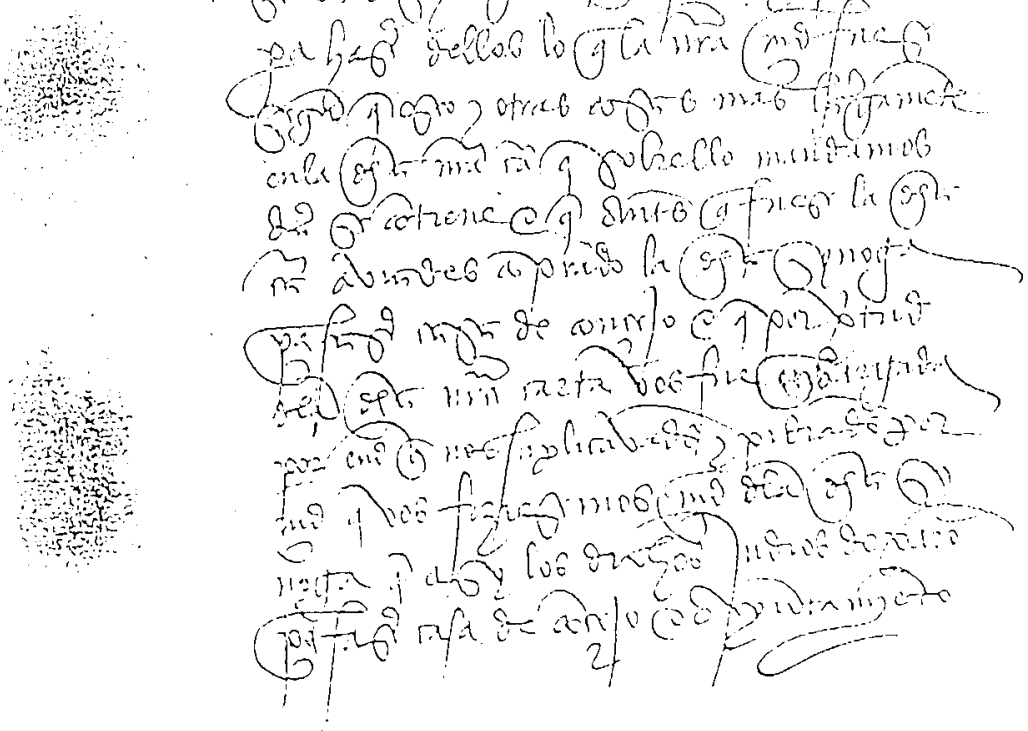

Apéndice $10^{\circ}$ bis 


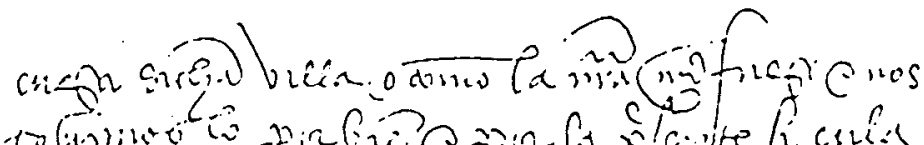

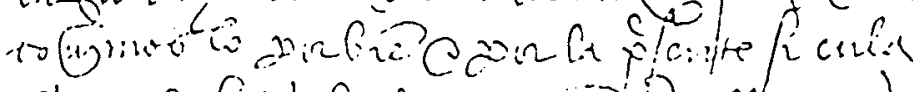

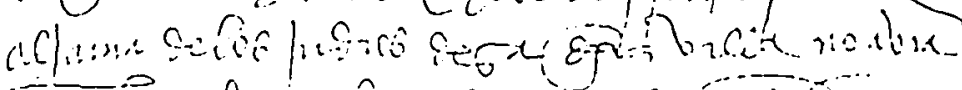

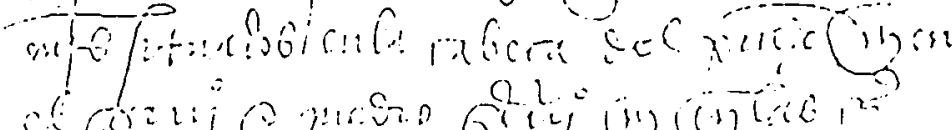

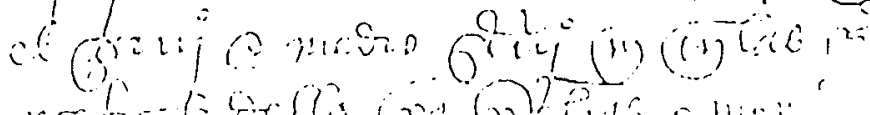

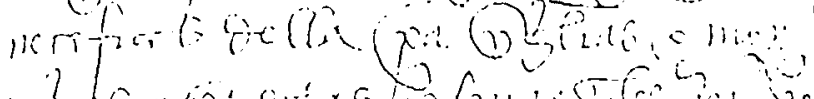

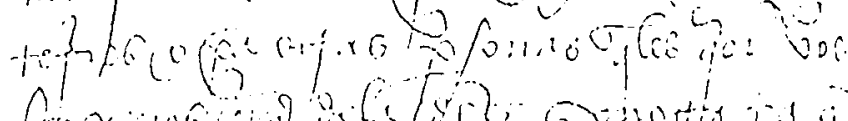

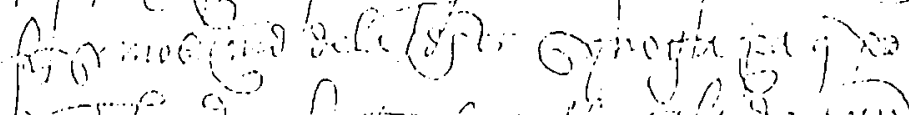
ary at

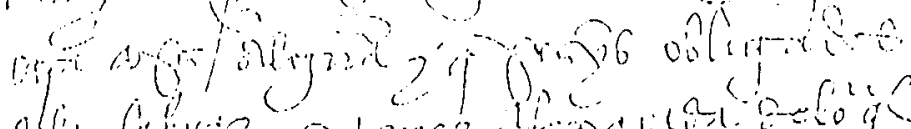

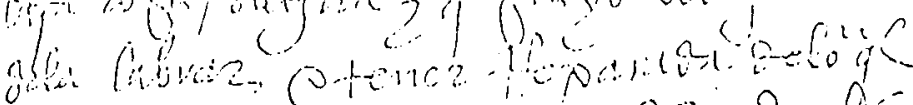
\%णn

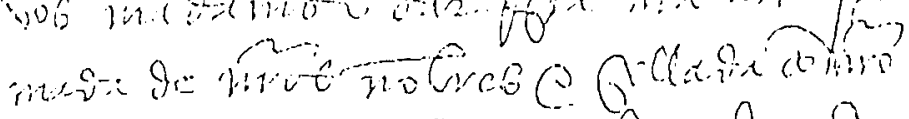

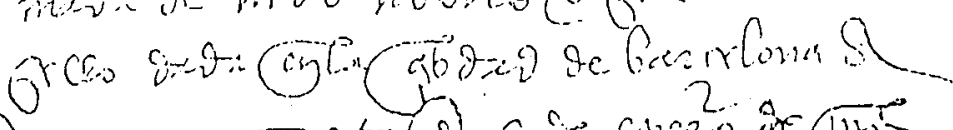

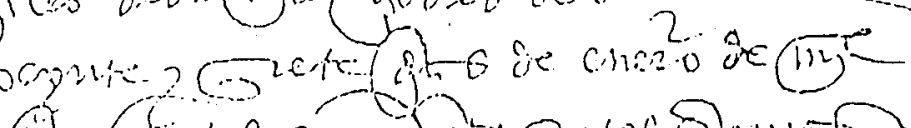

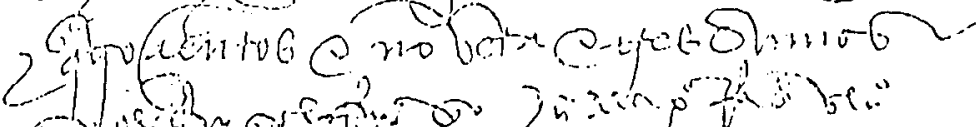
(3)

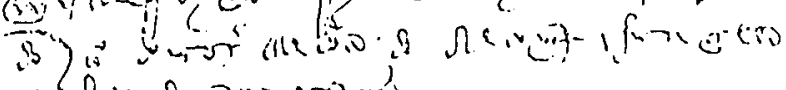

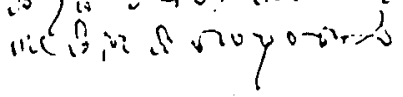

Apéndice $2^{\circ}$ 
Más aportaciones para el estudio de la aljama hebrea de la villa de Ágreda

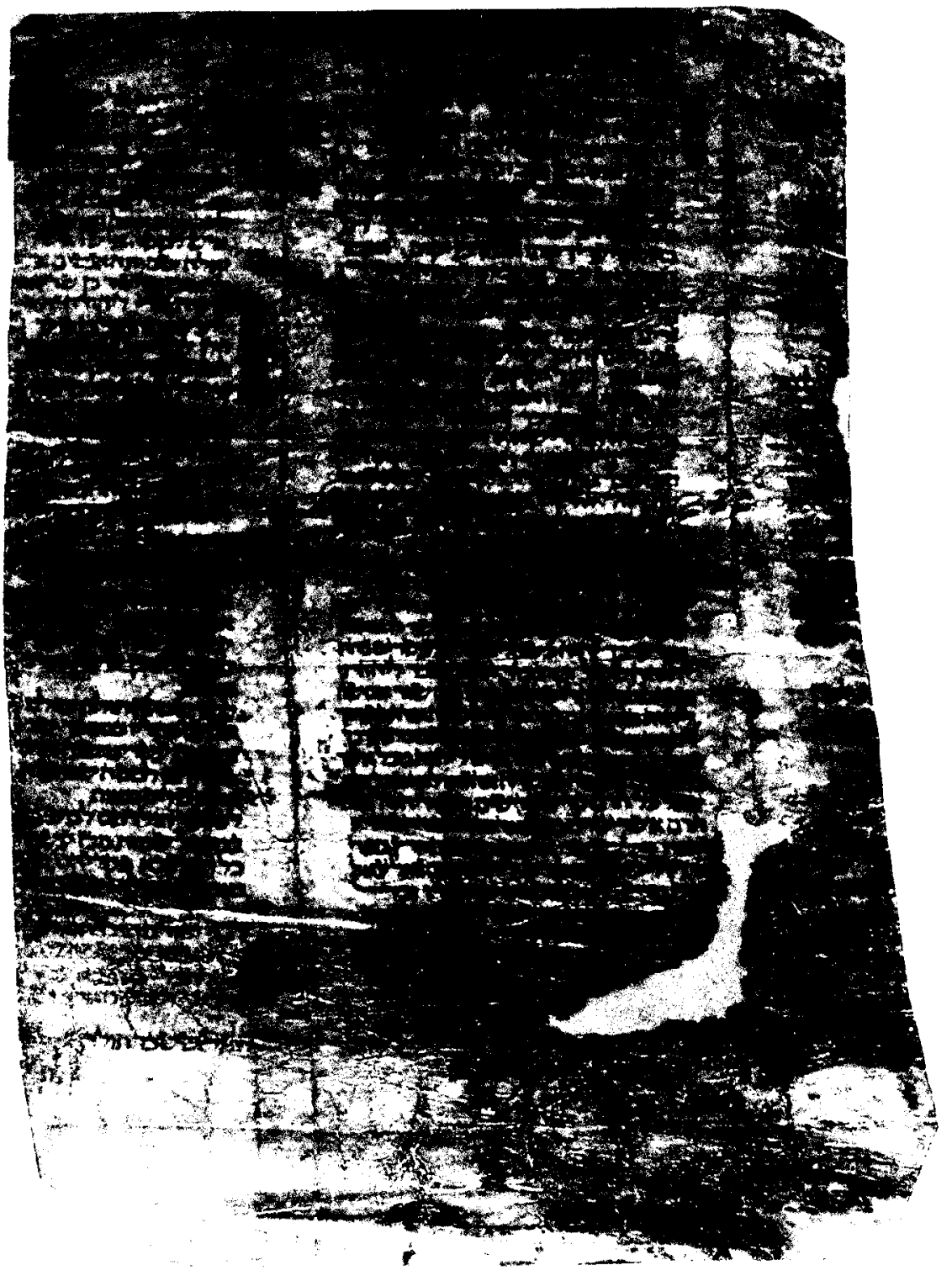

Apéndice $3 .^{\circ}$ 